\title{
Mechanical and Dynamic Properties of Hybrid Fiber Reinforced Fly-Ash Concrete
}

\author{
Dan-Yang Su, ${ }^{1,2}$ Jian-Yong Pang $\mathbb{D D}^{1,2}$ and Xiao-Wen Huang ${ }^{2}$ \\ ${ }^{1}$ State Key Laboratory of Mining Response and Disaster Prevention and Control in Deep Coal Mine, \\ Anhui University of Science and Technology, Huainan 232001, China \\ ${ }^{2}$ School of Civil Engineering and Architecture, Anhui University of Science and Technology, Huainan 232001, China \\ Correspondence should be addressed to Jian-Yong Pang; jypang@aust.edu.cn
}

Received 4 May 2021; Revised 13 June 2021; Accepted 1 August 2021; Published 10 August 2021

Academic Editor: Suvash Paul

Copyright (c) 2021 Dan-Yang Su et al. This is an open access article distributed under the Creative Commons Attribution License, which permits unrestricted use, distribution, and reproduction in any medium, provided the original work is properly cited.

In order to explore the influence of basalt-polypropylene hybrid fiber on the static mechanical properties and dynamic compression properties of fly-ash concrete, 16 groups of basalt-polypropylene hybrid fiber fly-ash concrete (HBPC) and 1 group of benchmark concrete were designed and prepared. The slump, static compressive strength, static splitting tensile strength, and dynamic compressive performance tests were tested. At the same time, the mechanism of the mechanical properties of hybrid fiber reinforced fly-ash concrete was analyzed by means of scanning electron microscopy (SEM). The results show that the failure of the benchmark concrete is mainly brittle failure. Compared with the benchmark concrete, the static compressive strength and splitting tensile strength of HBPC are significantly enhanced. Basalt-polypropylene hybrid fiber, polypropylene fiber, and basalt fiber, are extremely significant factors affecting the slump, static compressive strength, and static splitting tensile strength of HBPC, respectively. The peak stress of the benchmark concrete and HBPC increases with the increase of the loading air pressure, showing a certain strain rate effect. SEM shows that the fibers have good dispersibility in the concrete and good adhesion with the concrete matrix interface, but excessive fibers will cause fiber agglomeration, which increases the internal defects of HBPC.

\section{Introduction}

Since the famous British craftsman Aspdin invented Portland cement in 1824, concrete, a kind of multiphase composite material composed of sand, stone, cement, and water, has been widely used in various countries around the world. It has become one of the most widely used materials in civil engineering [1]. But the disadvantage of concrete is that it has low tensile strength and is prone to brittle failure. Once cracking occurs, it will lose its bearing capacity rapidly under the action of tensile stress, which limits the application of concrete in civil engineering to a certain extent. Therefore, how to effectively improve the mechanical properties of concrete has always been a hot topic in the engineering field all over the world $[2,3]$.

The splitting tensile strength of concrete is directly proportional to its compressive strength, but the tensioncompression ratio is inversely proportional to its strength grade [4-6]. Adding fiber into concrete can effectively improve the tension-compression ratio of concrete, that is, its tensile strength and toughness, and improve its brittle failure characteristics [7-9]. At present, the representative fibers are steel fiber, polypropylene fiber, basalt fiber, and synthetic fiber, and the research shows that [10-12] basalt fiber has low price, high elastic modulus, and little environmental pollution, and the splitting tensile property and durability of concrete can be improved obviously by adding it into concrete; adding polypropylene fiber into concrete can enhance the compressive strength and improve the brittle failure under compression of concrete.

Meanwhile, studies show that [13-17] when the tensile stress of concrete is less than the cracking stress, the tensile force is mainly borne by concrete, and the fiber bears less. When microcracks appear inside the component, the cracked concrete loses part of its load-bearing capacity, and the fibers that cross the microcracks begin to work, and 
microfibers with low elastic modulus can significantly inhibit the early primary microcracks. With the increase of the crack width, the microfibers are continuously pulled out and broken. At this time, the macrofibers with high elastic modulus begin to play a role, effectively delaying and preventing the expansion of cracks. Therefore, the addition of a kind of fiber into concrete has great limitations for the improvement of concrete performance, and the hybrid of two types of fibers can complement each other's advantages and better play the "positive hybrid effect."

Fly ash comes from the powder collected from the flue gas of pulverized coal combustion in the boiler, which has potential hydration activity and better characteristics of reducing hydration heat. In order to improve the utilization rate of waste fly ash, it is widely used in cement mixture, steamed lime-sand brick, concrete admixture, and other building materials [18-20]. At present, domestic and foreign scholars use fly ash to replace a certain proportion of cement as the cementing material to prepare concrete. Research shows that fly ash plays a promoting role in the later stage of coagulation. Within a reasonable cement replacement rate, the compressive strength and splitting tensile strength of fly ash instead of cement concrete are improved to varying degrees [21, 22].

In 1951, Japanese statistician Genichi Taguchi proposed the orthogonal table based on the optimization rule of the experiment. The orthogonal table has become the basic tool of the orthogonal experiment design, which makes the orthogonal experiment dispersibility and neat comparability. Not only can the order of the primary and secondary effects of the factors be determined according to the orthogonal table but also the range and variance analysis can be used to analyze the test data and the degree of influence of each factor on the index, so as to find the optimal conditions or the optimal combination to achieve the purpose of the test [23-25].

At present, the research and application of hybrid fiber concrete are mostly steel-polypropylene hybrid fiber concrete $[26,27]$, and the research on basalt fiber and polypropylene fiber mixed into concrete is less. Therefore, in this paper, basalt fiber and polypropylene fiber are mixed into concrete and fly ash is used to replace a small amount of cement to prepare basalt-polypropylene hybrid fiber fly-ash concrete. It is expected that the two kinds of fibers will play a "positive hybrid effect." In order to further study the influence of basalt fiber, polypropylene fiber and fly ash replace part of cement on the working performance, static mechanical performance, and dynamic compression performance of concrete, and the orthogonal experiments of basalt fiber volume ratio, polypropylene fiber volume ratio, and flyash replacing cement ratio were designed and tested on the slump, static compressive strength, static splitting tensile strength, and dynamic compressive performance of basaltpolypropylene hybrid fiber fly-ash concrete, to provide a theoretical basis for related engineering.

\section{Materials and Methods}

2.1. Raw Materials. The binder material, used in the experiment, consists of the Chinese standard Portland cement and fly ash. The cement adopts P.O 42.5 ordinary Portland cement, and it has $42.5 \mathrm{MPa}$ compressive strength at the age of $28^{\text {th }}$ day. Basalt fiber is chopped basalt fiber, and polypropylene fiber is single-tied polypropylene fiber, as shown in Figure 1. The main performance parameters of basalt fiber and polypropylene fiber are shown in Table 1. The coarse aggregate used in the experiment has the particle sizes of 5-25 mm continuous graded granite gravel with bulk density of $1465 \mathrm{~kg} / \mathrm{m}^{3}$, apparent density of $2665 \mathrm{~kg} / \mathrm{m}^{3}$, crushing index of $10.5 \%$, and mud content of $0.5 \%$. The sand selected in the experiment is natural river sand with apparent density of $2520 \mathrm{~kg} / \mathrm{m}^{3}$ and fineness modulus of 2.7 . The water-reducing agent was polycarboxylic acid superplasticizer (Type $\mathrm{F})$, and the water-reducing rate was $37 \%$. The water is ordinary tap water.

2.2. Experimental Design. Orthogonal experiment is an experimental method to arrange multifactor and multilevel experiments, which can effectively reduce the number of experiments when the number of total experiment groups is large. Its principle is to select representative and typical experimental groups from all experimental groups according to the orthogonality, so as to achieve the purpose of high efficiency, fast, and economy [28]. The factors and levels of this experiment are (1) basalt fiber volume ratio $V_{b}$ (factor $A$ ); (2) polypropylene fiber volume ratio $V_{p}$ (factor $B$ ); (3) fly ash replacing cement ratio $R_{f}$ (factor $C$ ). The orthogonal table adopts three factors and four levels, namely, L16 $\left(4^{3}\right)$ orthogonal test design, as shown in Table 2. The design of reference mix proportion is shown in Table 3.

2.3. Sample Preparation. Sodium carboxymethyl cellulose can make the fiber fully disperse in the concrete in the state of monofilament and improve the reinforcement effect of the fiber, and the influence on the performance of the concrete itself can be ignored, and its dosage is generally set as $0.7 \%$ of the total mass of the cementitious material [29]. In the trial mixing process, the agglomeration phenomenon is easily formed when the fiber volume ratio is too large, so sodium carboxymethyl cellulose is added to the sample. The wet mixing and fiber sprinkling were carried out simultaneously. Firstly, sand, gravel, and cementitious materials were mixed dry; then, water and water-reducing agent were added, and at the same time, fiber was sprinkled for wet mixing. Six $100 \mathrm{~mm} \times 100 \mathrm{~mm} \times 100 \mathrm{~mm}$ cube specimens (three of them are used for the cube compressive strength test and the other three are used for the splitting tensile strength test) are prepared for each group mix proportions. In the SHPB test, there is currently no unified standard for the size of the test piece, which is generally determined based on the diameter of the SHPB equipment bar and combined with experience. It must be free from friction and inertial force during the test, and the specimen is in overall stress balance and in a uniaxial stress state. At the same time, it is necessary to control the height-diameter ratio of the specimen to be $0.5 \sim 1.0$. According to the SHPB equipment in the laboratory, nine cylindrical specimens with a diameter of $74 \mathrm{~mm}$ and a height of $38 \mathrm{~mm}$ were 


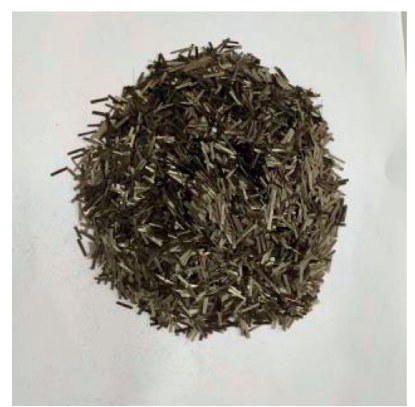

(a)

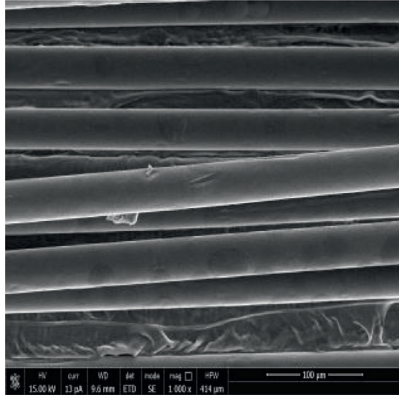

(b)

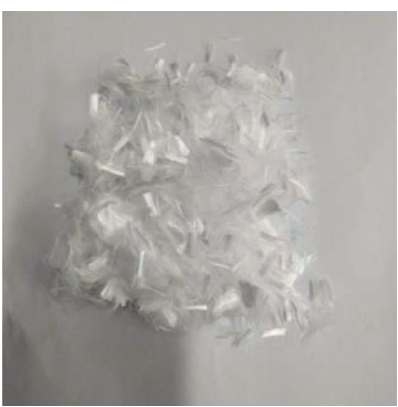

(c)

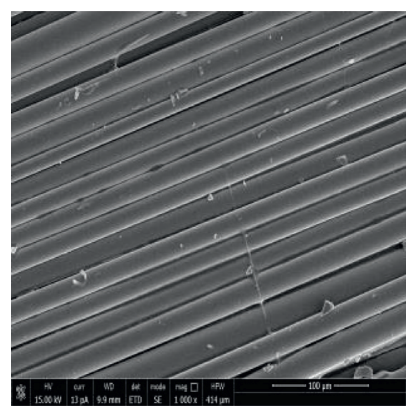

(d)

Figure 1: Appearance and microstructure of fiber: (a) appearance of basalt fiber, (b) microstructure of basalt fiber, (c) appearance of polypropylene fiber, and (d) microstructure of polypropylene fiber.

TABLE 1: Main performance parameters of basalt fiber and polypropylene fiber.

\begin{tabular}{lcc}
\hline Fiber & Basalt fiber & Polypropylene fibers \\
\hline Density $\left(\mathrm{g} / \mathrm{cm}^{3}\right)$ & 2.8 & 0.91 \\
Tensile strength $(\mathrm{MPa})$ & 4000 & 700 \\
Modulus of elasticity $(\mathrm{GPa})$ & 100 & 5.85 \\
Monofilament diameter $(\mu \mathrm{m})$ & 12 & 8 \\
Length $(\mathrm{mm})$ & 12 & 10 \\
Elongation at break $(\%)$ & 3.1 & 15 \\
\hline
\end{tabular}

TABLE 2: Orthogonal experiment factors and levels of HBPC.

\begin{tabular}{lccc}
\hline Level & \multicolumn{3}{c}{ Factor } \\
& $V_{b}(A)(\%)$ & $V_{p}(B)(\%)$ & $R_{f}(C)(\%)$ \\
\hline 1 & 0.1 & 0.1 & 5 \\
2 & 0.2 & 0.2 & 10 \\
3 & 0.3 & 0.3 & 15 \\
4 & 0.4 & 0.4 & 20 \\
\hline
\end{tabular}

Note: the percentage of basalt fiber and polypropylene fiber refers to the mass conversion relative to their respective densities, and the percentage of fly ash refers to the percentage of the quality of substitute cement.

TABLE 3: Benchmark mix proportions of concrete in $\mathrm{kg} / \mathrm{m}^{3}$.

\begin{tabular}{lcccc}
\hline Water & Cement & Sand & Gravel & Water-reducing agent \\
\hline 163 & 330 & 615 & 1243 & 5.2 \\
\hline
\end{tabular}

prepared for each group mix proportions. The static compressive strength, static splitting tensile strength, and dynamic compressive properties of the specimens were tested after 28 days of indoor standard curing under natural conditions. The curing temperature range was $16 \sim 24^{\circ} \mathrm{C}$, and the humidity was more than $95 \%$.

\subsection{Static Mechanical Property Test}

2.4.1. Test Methods. Compressive strength and splitting tensile strength were tested by using the YAW-4206 pressure testing machine. According to the regulations' provisions of the National Standards of the People's Republic of China (GB/T 50081-2002) Standard for test method of mechanical properties of ordinary concrete, the standard size of the specimen used to measure the compressive strength and splitting tensile strength of concrete is $150 \mathrm{~mm} \times 150 \mathrm{~mm} \times 150 \mathrm{~mm}$. Because the specimen is $100 \mathrm{~mm} \times 100 \mathrm{~mm} \times 100 \mathrm{~mm}$ nonstandard specimen, the cube compressive strength and splitting tensile strength are converted into standard specimen results by multiplying the size conversion coefficient. The cube compressive strength size coefficient is 0.95 , and splitting tensile strength size coefficient is 0.85 .

2.4.2. Data Processing. In order to investigate the effects of basalt fiber volume ratio $(A)$, polypropylene fiber volume ratio $(B)$, and fly-ash replacing cement ratio $(C)$ on the slump, static compressive strength, and static splitting tensile strength of HBPC, find out the significant factors, and calculate the range and variance results of slump, compressive strength, splitting tensile strength, and tensioncompression ratio of HBPC. The calculation method is as follows:

The range calculation method is as follows:

$$
R_{i}=\max \left(\overline{K_{i 1}}, \overline{K_{i 2}}, \ldots, \overline{K_{i m}}\right)-\min \left(\overline{K_{i 1}}, \overline{K_{i 2}}, \ldots, \overline{K_{i m}}\right) \quad(i=A, B \text {, and } C ; m=1,2,3 \text {, and } 4)
$$

where $K_{i m}$ is the sum of the test results corresponding to the level of factor $m$ in column $i, \overline{K_{i m}}$ is the average value of $K_{i m}$, and $R_{i}$ is the range of factors in column $i$.
$R_{i}$ reflects the change range of the test index when the level of the factors in column $i$ changes. The larger $R_{i}$ is, the greater the influence of the factor on the test index is. 
Therefore, the primary and secondary relationship of the factors can be judged according to $R_{i}$.

The variance is calculated as follows:

Sum of squares of total deviations : SST $=\sum_{i=1}^{n}\left(y_{i}-\bar{y}\right)^{2}$,

$$
\text { Degree of freedom : } f_{t}=n-1 \text {, }
$$

where $n$ is the number of rows (test times) of the orthogonal experiment table and $\bar{y}$ is the average value of $n$ test indexes:

$$
\text { Mean square of factor } A: \text { MSA }=\frac{\text { SSA }}{f_{A}},
$$

where $A$ is the level number of factor $A, n_{i}$ is the number of tests at level $i$, and $\overline{y_{i}}$ is the average value of index at each level of factor $A$. Similar to the solution of the sum of square sum of deviation, degree of freedom, and mean square of factor $A$, the values of SSB, SSC, $f_{B}, f_{C}, \mathrm{MSB}$, and MSC can be obtained:
Degree of freedom : $f_{A}=n_{i}-1$,

$$
\begin{aligned}
\text { Sum of the squares of deviation of error }: \text { SSE } & =\text { SST }- \text { SSA }- \text { SSB }- \text { SSC, } \\
\text { Mean square of error : MSE } & =\frac{\text { SSE }}{f_{E}}, \\
\text { Significant level of factor } A: F_{A} & =\frac{\mathrm{MSA}}{\mathrm{MSE}} .
\end{aligned}
$$

Similar to the significance level of factor $A, F_{B}$ and $F_{C}$ can be obtained.

\subsection{Dynamic Compression Performance Test}

2.5.1. Test Rig. The dynamic mechanical properties' test used a variable cross-section SHPB system with a diameter of $74 \mathrm{~mm}$, as shown in Figure 2. The test rig is mainly composed of the loading drive system, compressive bar system, and data acquisition system.

2.5.2. Test Principle. The rods in the press bar system are all made of uniform steel material; the specific parameters are as follows: the striker bar is a constant cross-section cylinder steel pole, with a total length of $800 \mathrm{~mm}$ and a diameter of $37 \mathrm{~mm}$. The incident bar is a variable cross-section steel pole, the total length is $3200 \mathrm{~mm}$, the variable cross-section area is $450 \mathrm{~mm}$ long, the diameter of the incident end is $37 \mathrm{~mm}$, and the diameter of the straight section is $74 \mathrm{~mm}$. The transmission bar is a constant cross-section cylinder steel pole, with a total length of $1600 \mathrm{~mm}$ and a diameter of $74 \mathrm{~mm}$.

As shown in Figure 3, driven by the high-pressure gas, the striker bar hits the incident bar at a certain initial velocity $v_{0}$. At the moment of impact, a forwardpropagating stress pulse, namely, the incident wave $\varepsilon_{i}$, is generated in the incident bar. When the incident wave propagates along the incident bar to the contact surface between the specimen and the incident bar, the specimen begins to deform or even break, and a reverse stress pulse is generated in the incident bar, that is, reflection wave $\varepsilon_{r}$. There is also a part of the stress pulse that penetrates the specimen into the transmission bar, continues to propagate forward, and generates a transmission stress pulse in the transmission bar, that is, a transmission wave $\varepsilon_{t}$.

The incident wave and the reflection wave are measured by the strain gauge on the incident bar, and the transmission wave is measured by the strain gauge voltage signal on the transmission bar. The voltage signal on the strain gauge is relatively weak and needs to be processed by a strain amplifier. The wiring method is a half-bridge type. The strain gauges are arranged in a symmetrical position for series connection, and the same type of strain gauge with the same resistance value is connected as temperature compensation. According to the one-dimensional elastic stress wave theory, the average strain $\varepsilon$, mean stress $\sigma$, and average strain rate $\varepsilon^{\prime}$ of the specimen were deduced by using the "three-wave method:"

$$
\begin{aligned}
\varepsilon & =\frac{c_{0}}{l_{0}} \int_{0}^{t}\left(\varepsilon_{i}-\varepsilon_{r}-\varepsilon_{t}\right) \mathrm{d} t, \\
\sigma & =\frac{A E}{2 A_{0}}\left(\varepsilon_{i}+\varepsilon_{r}+\varepsilon_{t}\right), \\
\mathcal{E}^{\prime} & =\frac{c_{0}}{l_{0}}\left(\varepsilon_{i}-\varepsilon_{r}-\varepsilon_{t}\right) .
\end{aligned}
$$

In formulae (10)-(12), $A$ is the cross-sectional area of the pressure rod, $E$ is the elastic modulus of the rod, $A_{0}$ is the cross-sectional area of the test piece, $l_{0}$ is the original length 


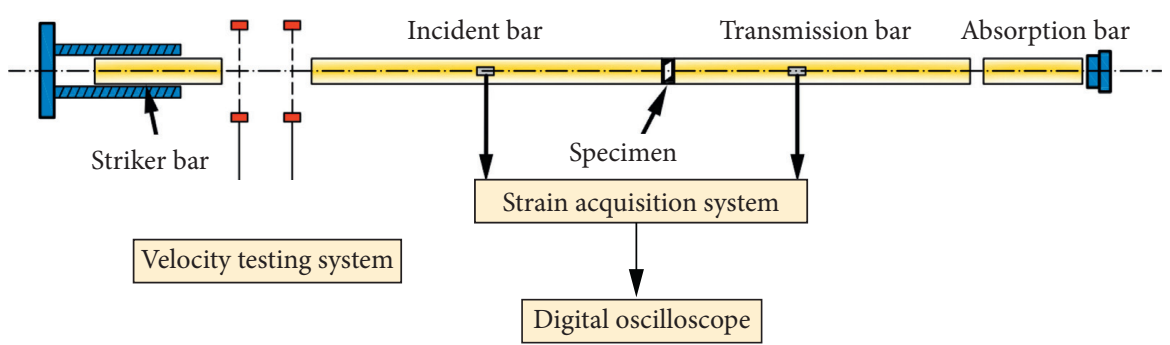

(a)

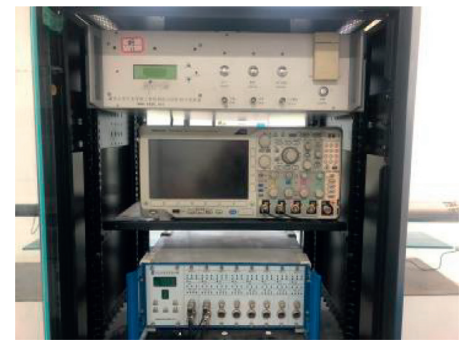

(c)

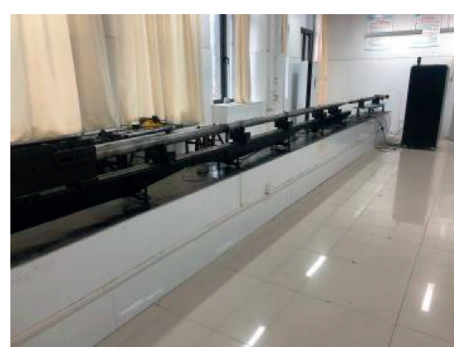

(b)

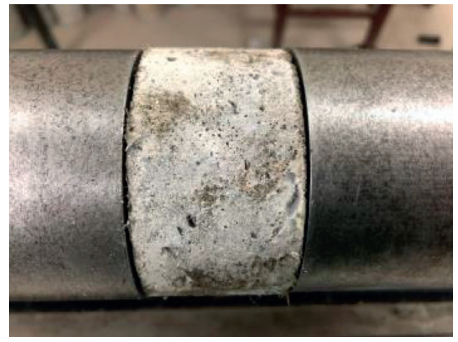

(d)

FIgURE 2: SHPB device. (a) SHPB equipment diagram. (b) Overall diagram. (c) Control and data acquisition system. (d) Specimen arrangement.

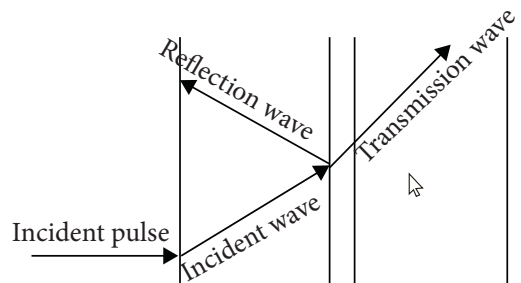

High pressure gas

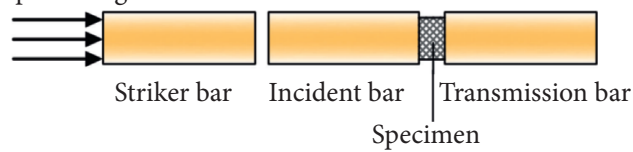

FIGURE 3: Schematic diagram of stress wave propagation.

of the test piece, $c_{0}$ is the elastic wave velocity in the rod, and $t$ is the action time of the stress pulse.

2.5.3. Test Plan. In this test, the loading air pressure is set to $0.4 \mathrm{MPa}, 0.5 \mathrm{MPa}$, and $0.6 \mathrm{MPa}$, which represent three strain rates of low, medium, and high, respectively. Each group of specimens is subjected to three shock tests under the same loading air pressure in order to obtain a more ideal test result. In order to keep the specimen surface in close contact with the transmission bar and the incident bar, before the test, adjust the axis position of the incident bar and the transmission bar, keep the two bars aligned with the support line and radial line, and fine-tune the height of the rod end support to ensure the two rods are aligned. Before the start of the test, in order to eliminate the influence of friction on the end face of the specimen, both ends of the specimen were evenly smeared with vaseline, and then, place the specimen in the center between the incident bar and the transmission bar.

\section{Static Mechanical Performance Test Results and Analysis}

3.1. Test Result. The slump, static compressive strength $\left(f_{c u}\right)$, static splitting tensile strength $\left(f_{t s}\right)$, and tension-compression ratio $\left(f_{t s} / f_{c u}\right)$ of a group of benchmark concrete and 16 groups of HBPC obtained from the test are listed in Table 4.

It can be seen from Table 4 that the compressive strength and splitting tensile strength of 16 groups of HBPC are higher than the benchmark concrete, and the maximum compressive strength appears in group $11^{\#}$, which is $20.87 \%$ higher than the benchmark concrete, and the maximum splitting tensile strength appears in group $15^{\#}$, which is $37.65 \%$ higher than the benchmark concrete.

3.2. Range Analysis. The range of slump, compressive strength, splitting tensile strength, and tension-compression ratio of HBPC is shown in Figure 4.

It can be seen from Figure 4(a) that the influence degree of three factors on the slump of HBPC is as follows: basalt fiber volume ratio $\left(V_{b}\right)>$ polypropylene fiber volume ratio $\left(V_{p}\right)>$ fly-ash cement replacement ratio $\left(R_{f}\right)$. With the increase of $V_{b}, V_{p}$, and $R_{f}$, the slump of HBPC all shows a downward trend. $V_{b}$ increased from $0.1 \%$ to $0.4 \%$, slump decreased by $65.84 \%, V_{p}$ increased from $0.1 \%$ to $0.4 \%$, slump decreased by $44.53 \%, R_{f}$ increased from $0.1 \%$ to $0.4 \%$, and slump decreased by $11.59 \%$. From the slump point of view, the best combination is $A_{1} B_{1} C_{1}$, that is, $V_{b}$ is $0.1 \%, V_{p}$ is $0.1 \%$, and $R_{f}$ is $5 \%$.

It can be seen from Figure 4(b) that the order of the influence of the three factors on the compressive strength of HBPC is as follows: $V_{p}$ (range: $\left.2.7 \mathrm{MPa}\right)>V_{b}$ (range: $2.07 \mathrm{MPa})>R_{f}$ (range: $\left.1.77 \mathrm{MPa}\right) . V_{b}$ increased from $0.1 \%$ to $0.4 \%$, the compressive strength increased by $3.68 \%, V_{p}$ 
TABLE 4: Slump and strength test results of HBPC.

\begin{tabular}{|c|c|c|c|c|}
\hline Sample & Concrete slump (mm) & $f_{c u}(\mathrm{MPa})$ & $f_{t s}(\mathrm{MPa})$ & $f_{t s} / f_{c u}$ \\
\hline $0^{\#}$ & 179 & 20.3 & 1.58 & 0.07798 \\
\hline $1^{\#}$ & 170 & 24.2 & 1.99 & 0.08211 \\
\hline $2^{\#}$ & 146 & 24.6 & 2.0 & 0.08121 \\
\hline $3^{\#}$ & 127 & 26.6 & 2.36 & 0.08866 \\
\hline $4^{\#}$ & 84 & 25.3 & 2.27 & 0.08992 \\
\hline $5^{\#}$ & 140 & 25.5 & 2.25 & 0.08832 \\
\hline $6^{\#}$ & 123 & 25.9 & 2.2 & 0.08476 \\
\hline $7^{\#}$ & 80 & 25.6 & 2.32 & 0.0908 \\
\hline $8^{\#}$ & 96 & 27.2 & 2.37 & 0.08713 \\
\hline $9^{\#}$ & 109 & 24.8 & 2.32 & 0.09356 \\
\hline $10^{\#}$ & 94 & 25.3 & 2.33 & 0.09218 \\
\hline $11^{\#}$ & 78 & 29.4 & 2.48 & 0.08425 \\
\hline $12^{\#}$ & 68 & 29 & 2.54 & 0.08757 \\
\hline $13^{\#}$ & 75 & 24.6 & 2.37 & 0.09624 \\
\hline $14^{\#}$ & 44 & 25.7 & 2.43 & 0.09469 \\
\hline $15^{\#}$ & 35 & 28.8 & 2.59 & 0.08983 \\
\hline $16^{\#}$ & 26 & 28.2 & 2.48 & 0.08796 \\
\hline
\end{tabular}

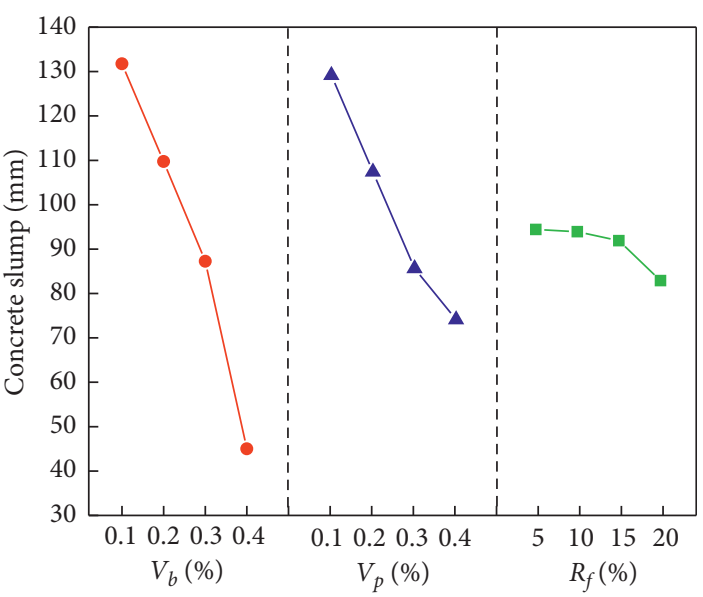

(a)

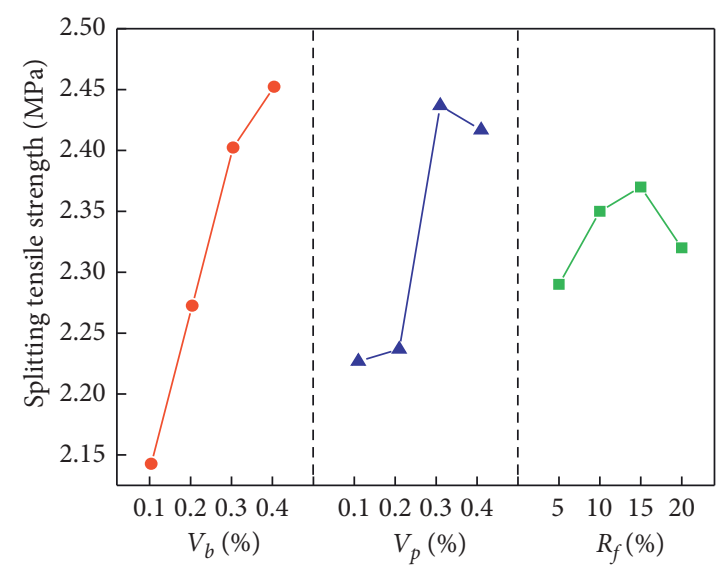

(c)

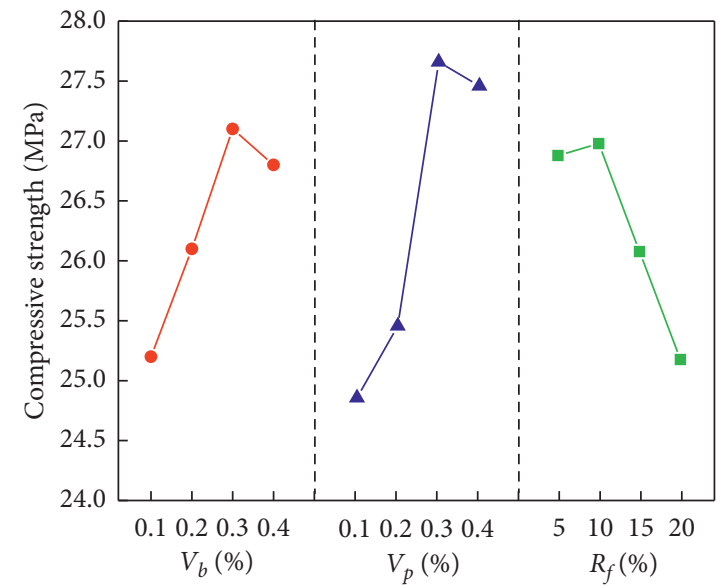

(b)

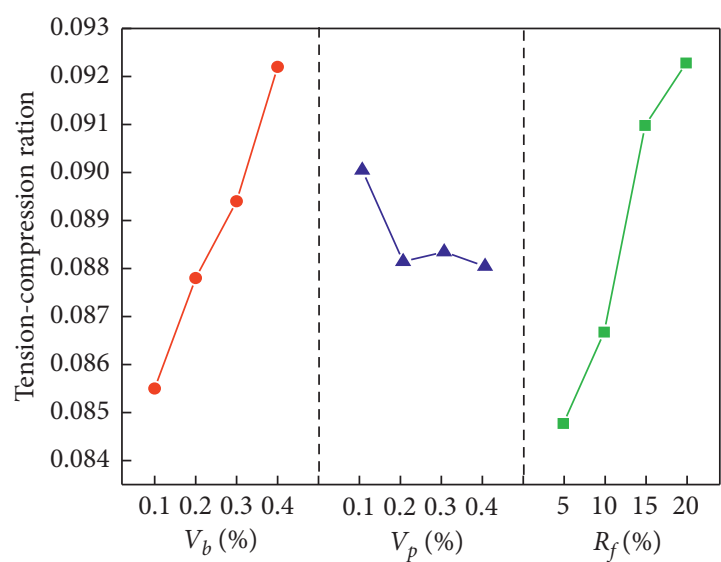

(d)

FIGURE 4: Range analysis results of three factors on mechanical properties of HBPC. (a) Slump. (b) Compressive strength. (c) Splitting tensile strength. (d) Tension-compression ratio.

increased from $0.1 \%$ to $0.4 \%$, and the compressive strength increased by $5.49 \% ; R_{f}$ increased from $0.1 \%$ to $0.4 \%$, and the compressive strength decreased by $3.44 \%$. The influence of
$R_{f}$ on compressive strength is not obvious, and the overall change is within $4 \%$. The compressive strength of HBPC increases first and then decreases with addition of fibers, 
indicating that a reasonable fiber volume ratio is conducive to the improvement of compressive strength, but too high fiber volume ratio will have a negative effect on compressive strength. From the perspective of compressive strength, the best combination is $A_{3} B_{3} C_{1}$, that is, $V_{b}$ is $0.3 \%, V_{p}$ is $0.3 \%$, and $R_{f}$ is $5 \%$.

It can be seen from Figure 4(c) that the factors influence the splitting tensile strength of $\mathrm{HBPC}$ are $V_{b}$ (range: $0.48 \mathrm{MPa})>R_{f}($ range: $0.22 \mathrm{MPa})>V_{p}($ range: $0.19 \mathrm{MPa}) . V_{b}$ increased from $0.1 \%$ to $0.4 \%$, splitting tensile strength increased by $11.61 \%, V_{p}$ increased from $0.1 \%$ to $0.4 \%$, splitting tensile strength increased by $3.23 \%, R_{f}$ increased from $0.1 \%$ to $0.4 \%$, and splitting tensile strength increased by $5.05 \%$. The influence of $V_{b}$ on the splitting tensile strength of HBPC is greater than that of $V_{p}$ and $R_{f}$, and the latter two have similar influences on the splitting tensile strength of HPBC. The addition of basalt fiber and polypropylene fiber is conducive to the improvement of HBPC splitting tensile strength, but the effect of polypropylene fiber on the splitting tensile strength of HBPC is less obvious than that of basalt fiber. This is mainly due to the high elastic modulus of basalt fiber, which bears more load than polypropylene fiber in the later stage of concrete cracking, which effectively prevents the expansion of concrete cracks $[30,31]$. It shows that fiber hybrids can exhibit good synergy, and the splitting tensile strength of the benchmark concrete can be improved. From the perspective of splitting tensile strength, and the best combination is $A_{4} B_{3} C_{2}$, that is, $V_{b}$ is $0.4 \%, V_{p}$ is $0.3 \%$, and $R_{f}$ is $10 \%$.

It can be seen from Figure 4(d) that the influence degree of three factors on the tension-compression ratio of HBPC is as follows: $R_{f}>V_{b}>V_{p} . V_{b}$ and $R_{f}$ have an increasing trend in the influence of HBPC tension-compression ratio, $V_{b}$ increased from $0.1 \%$ to $0.4 \%$, tension-compression ratio increased by $7.84 \%, V_{b}$ increased from $5 \%$ to $20 \%$, and tension-compression ratio increased by $8.86 \%$. With the increase of $V_{p}$, the tension-compression ratio first decreases, then increases, and then decreases, but the overall variation range is within $3 \%$, and the influence is not obvious. If only considering the improvement of the concrete tensioncompression ratio, the optimal combination is $A_{4} B_{1} C_{4}$, that is, $V_{b}$ is $0.4 \%, V_{p}$ is $0.1 \%$, and $R_{f}$ is $20 \%$.

3.3. Variance Analysis. The variance calculation results are listed in Table 5. $V_{b}$ and $V_{p}$ are extremely significant factors for HBPC slump, $R_{f}$ is an nonsignificant factor, $V_{p}$ is an extremely significant factor for HBPC compressive strength, $V_{b}$ and $R_{f}$ are significant factors, $V_{b}$ is an extremely significant factor for HBPC splitting tensile strength, $V_{p}$ and $R_{f}$ are significant factors, and fly ash is more significant than polypropylene fiber; $R_{f}$ is an extremely significant factor for the HBPC tension-compression ratio, $V_{b}$ is an significant factor, and $V_{p}$ is a nonsignificant factor that affects the tension-compression ratio of HBPC.

3.4. Analysis of HBPC Efficacy Coefficient Method. The efficacy coefficient method is a comprehensive evaluation method for multiple objectives. According to the results of slump, compressive strength, and splitting tensile strength of HBPC in Table 5, the maximum and minimum values are selected as the satisfactory and unallowable values of the efficacy coefficient method index evaluation system. The specific values are shown in Table 6 .

Calculate the efficiency coefficient values of each index of 16 groups of HBPC according to the satisfactory value and the unallowable value of each index. The calculation formula is as follows:

$$
d_{i}=\frac{\text { Actual value }- \text { Unallowable value }}{\text { Satisfactory value }- \text { Unallowable value }} \times 40+60 \quad(i=1,2 \text {, and } 3),
$$

where $d_{1}$ is the efficacy coefficient value of each group of HBPC slump, $d_{2}$ is the efficacy coefficient value of each group of HBPC compressive strength, and $d_{3}$ is the efficacy coefficient value of each group of HBPC splitting tensile strength:

Total efficacy coefficient value of each group of HBPC: $d=\sqrt[3]{d_{1} \times d_{2} \times d_{3}}$.

The calculation results are shown in Table 7.

According to the comparison of the total efficacy coefficient values of the data in Table 7 , the total efficacy coefficient of the specimens in $12^{\#}$ group is the largest, which is 87.84. Therefore, combining the three indexes of slump, compressive strength, and split tensile strength, the best mix ratio combination is $A_{3} B_{4} C_{2}$.
3.5. Failure Mode Analysis. Figure 5 shows the failure mode of part of specimens under the static compressive strength test, and Figure 6 shows the failure mode of the part of specimens' static splitting tensile strength. In the static compressive strength test, the $0^{\#}$ group, the benchmark concrete specimen, shows obvious damage and large flaking, while the surface of the concrete specimen mixed with basalt 
TABLE 5: HBPC slump and strength variance analysis results.

\begin{tabular}{|c|c|c|c|c|c|c|}
\hline Index & Sources of variation & Sum of square & Mean square & Freedom & $F$ value & Significance \\
\hline \multirow{4}{*}{ Concrete slump (mm) } & $A$ & 16473.7 & 5491.2 & 3 & 43.37 & $* *$ \\
\hline & $B$ & 7101.2 & 2367.1 & 3 & 18.7 & $* *$ \\
\hline & C & 609.7 & 203.2 & 3 & 1.61 & - \\
\hline & $E$ & 759.4 & 126.6 & 6 & & \\
\hline \multirow{4}{*}{$f_{c u}(\mathrm{MPa})$} & $A$ & 10.303 & 3.434 & 3 & 14.77 & $*$ \\
\hline & $B$ & 23.288 & 7.763 & 3 & 33.39 & $* *$ \\
\hline & $C$ & 8.692 & 2.898 & 3 & 12.46 & $*$ \\
\hline & $E$ & 1.395 & 0.233 & 6 & & \\
\hline \multirow{4}{*}{$f_{t s}(\mathrm{MPa})$} & $A$ & 0.525 & 0.175 & 3 & 19.74 & $* *$ \\
\hline & $B$ & 0.112 & 0.037 & 3 & 4.2 & $*$ \\
\hline & $C$ & 0.131 & 0.044 & 3 & 4.92 & $*$ \\
\hline & $E$ & 0.053 & 0.009 & 6 & & \\
\hline \multirow{4}{*}{$f_{t s} / f_{c u}$} & $A$ & 0.000096 & 0.000032 & 3 & 9.84 & $*$ \\
\hline & $B$ & 0.00001 & 0.000003 & 3 & 1.03 & - \\
\hline & $C$ & 0.00015 & 0.00005 & 3 & 15.46 & $* *$ \\
\hline & $E$ & 0.000019 & 0.000003 & 6 & & \\
\hline
\end{tabular}

Note: ${ }^{* *}$ represents extremely significant, ${ }^{*}$ represents significant, and - represents nonsignificant.

TABLE 6: Satisfactory and unallowable values of each index.

\begin{tabular}{lccc}
\hline Value type & Slump $(\mathrm{mm})$ & Compressive strength $(\mathrm{MPa})$ & Splitting tensile strength $(\mathrm{MPa})$ \\
\hline Satisfactory value & 170 & 52.7 & 4.68 \\
Unallowable value & 26 & 47.5 & 3.89 \\
\hline
\end{tabular}

TABLE 7: HBPC efficacy coefficient analysis results.

\begin{tabular}{|c|c|c|c|c|c|c|c|}
\hline \multirow[b]{2}{*}{ Sample } & \multicolumn{3}{|c|}{ Index } & \multicolumn{3}{|c|}{ Efficiency coefficient } & \multirow{2}{*}{$\begin{array}{c}\text { Total efficacy } \\
\text { coefficient }\end{array}$} \\
\hline & $\begin{array}{c}\text { Concrete } \\
\text { slump }(\mathrm{mm})\end{array}$ & $\begin{array}{l}\text { Compressive } \\
\text { strength (MPa) }\end{array}$ & $\begin{array}{l}\text { Splitting tensile } \\
\text { strength }(\mathrm{MPa})\end{array}$ & $\begin{array}{c}\text { Concrete } \\
\text { slump }(\mathrm{mm})\end{array}$ & $\begin{array}{c}\text { Compressive } \\
\text { strength }(\mathrm{MPa})\end{array}$ & $\begin{array}{l}\text { Splitting tensile } \\
\text { strength }(\mathrm{MPa})\end{array}$ & \\
\hline $1^{\#}$ & 170 & 24.2 & 1.99 & 100 & 60 & 60.51 & 71.34 \\
\hline $2^{\#}$ & 146 & 24.6 & 2.0 & 93.33 & 63.08 & 60 & 70.69 \\
\hline $3^{\#}$ & 127 & 26.6 & 2.36 & 88.06 & 74.62 & 84.81 & 82.29 \\
\hline $4^{\#}$ & 84 & 25.3 & 2.27 & 76.11 & 68.46 & 84.3 & 76.02 \\
\hline $5^{\#}$ & 140 & 25.5 & 2.25 & 91.67 & 70 & 81.27 & 80.49 \\
\hline $6^{\#}$ & 123 & 25.9 & 2.2 & 86.94 & 73.08 & 74.18 & 77.82 \\
\hline $7^{\#}$ & 80 & 25.6 & 2.32 & 75 & 70.77 & 87.85 & 77.54 \\
\hline $8^{\#}$ & 96 & 27.2 & 2.37 & 79.44 & 83.08 & 85.82 & 82.74 \\
\hline $9^{\#}$ & 109 & 24.8 & 2.32 & 83.06 & 64.62 & 90.89 & 78.72 \\
\hline $10^{\#}$ & 94 & 25.3 & 2.33 & 78.89 & 68.46 & 89.87 & 78.59 \\
\hline $11^{\#}$ & 78 & 29.4 & 2.48 & 74.44 & 100 & 87.85 & 86.80 \\
\hline $12^{\#}$ & 68 & 29 & 2.54 & 71.67 & 96.92 & 94.94 & 87.04 \\
\hline $13^{\#}$ & 75 & 24.6 & 2.37 & 73.61 & 63.08 & 96.46 & 76.51 \\
\hline $14^{\#}$ & 44 & 25.7 & 2.43 & 65 & 71.54 & 97.97 & 76.95 \\
\hline $15^{\#}$ & 35 & 28.8 & 2.59 & 62.5 & 95.38 & 100 & 84.16 \\
\hline $16^{\#}$ & 26 & 28.2 & 2.48 & 60 & 90.77 & 92.41 & 79.54 \\
\hline
\end{tabular}

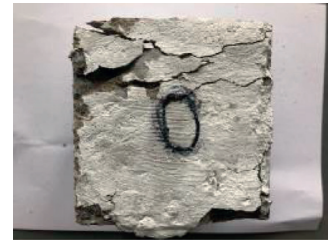

(a)

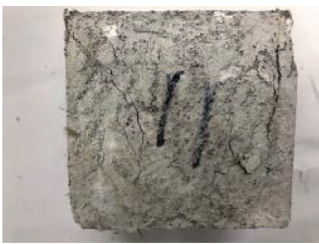

(b)

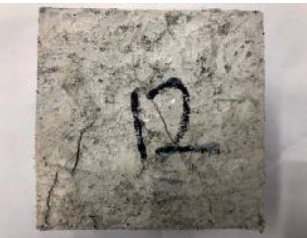

(c)

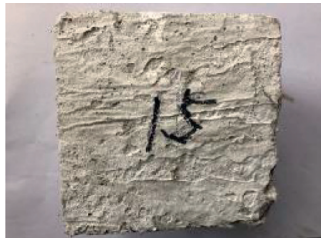

(d)

Figure 5: Failure modes of specimens in the static compressive strength test. (a) $0^{\#}$ group. (b) $11^{\#}$ group. (c) $12^{\#}$ group. (d) $15^{\#}$ group. 


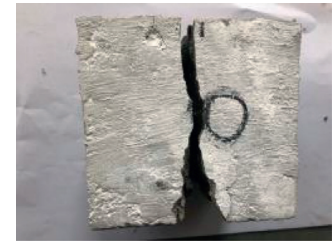

(a)

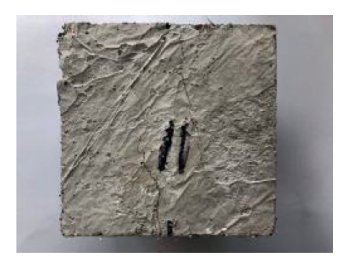

(b)

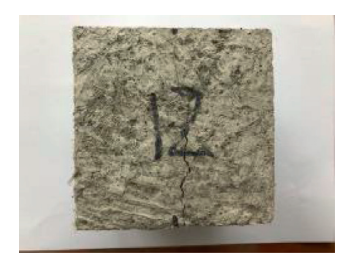

(c)

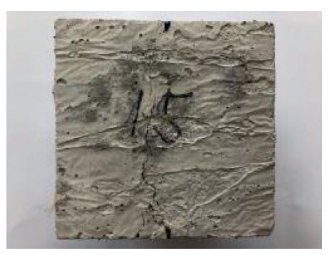

(d)

Figure 6: Failure modes of specimens in the static splitting tensile strength test. (a) $0^{\#}$ group. (b) $11^{\#}$ group. (c) $12^{\#}$ group. (e) $15^{\#}$ group.

fiber, polypropylene fiber, and fly ash is relatively complete, with only small cracks on the surface and small peeling off at the corners; in the static splitting tensile strength, the benchmark concrete showed obvious brittle failure, the specimen fractured into two halves, accompanied by a larger sound when it is destroyed, while the specimens of the $11^{\#}$, $12^{\#}$, and $15^{\#}$ groups were not split into two parts after being destroyed, and the main crack appeared on the surface of the specimen. The integrity of the specimen was better, showing a phenomenon of cracking but not scattering, and the sound was dull when it was destroyed.

3.6. HBPC Strength Prediction Model. According to the theory of mechanics composite materials, it can be assumed that the strength of HBPC is composed of concrete original strength, basalt fiber reinforcement, polypropylene fiber reinforcement, and fly ash instead of cement reinforcement.

Assume that the strength regression model is as follows:

$$
f=\alpha_{0}+\alpha_{1} x_{1}+\alpha_{2} x_{2}+\alpha_{3} x_{3}+\phi,
$$

where $f$ is the concrete compressive strength or split tensile strength $(\mathrm{MPa}), \alpha_{0}$ is the concrete matrix compressive strength or split tensile strength ( $\mathrm{MPa}), \alpha_{1}, \alpha_{2}$, and $\alpha_{3}$ is the regression coefficient, $\varphi$ is the test parameter, $x_{1}$ is the basalt fiber volume ratio (\%), $x_{2}$ is the polypropylene fiber volume ratio (\%), and $x_{3}$ is the fly-ash replacing cement ratio (\%).

Substituting the data in Table 4 into regression model (15), the least squares method is used to estimate $\alpha_{0}$ to obtain the regression equation of HBPC compressive strength and splitting tensile strength:

$$
\begin{gathered}
f_{c u}=47+640 x_{1}+1005 x_{2}-12.4 x_{3} \quad\left(R^{2}=0.83\right), \\
f_{t s}=3.65+161 x_{1}+61 x_{2}+152 x_{3} \quad\left(R^{2}=0.86\right) .
\end{gathered}
$$

In formulae (16) and (17), $f_{c u}$ is the compressive strength of HBPC (MPa), $f_{t s}$ is the splitting tensile strength of HBPC $(\mathrm{MPa})$, and $R^{2}$ is the coefficient of determination.

Figure 7 shows the relative error comparison between the predicted and measured values of HBPC compressive strength and splitting tensile strength. It can be seen that the maximum error occurs in $0^{\#}$ group, with an error of $7.8 \%$, indicating that the model has high accuracy and can provide certain reference value for engineering construction.

\section{Dynamic Compression Performance Test Results and Analysis}

4.1. Stress Balance Verification. During the shock test, whether the stress at both ends of the specimen can be balanced before failure determines the reliability of the test results [32]. Therefore, the data balance needs to be verified before the start of the experiment, and the verification basis is $\varepsilon_{i}(t)+\varepsilon_{r}(t)=\varepsilon_{t}(t)$. Figure 8 is the stress balance at both ends of the assembly. It can be seen that the sum of the incident stress and the reflection stress is basically equal to the transmission stress, the stresses at both ends of the specimen are balanced, and the test results are reliable.

4.2. HBPC Failure Mode. The failure mode of the typical HBPC specimens after the dynamic compression mechanical properties test is selected for analysis, and the $0^{\#}, 11^{\#}, 12^{\#}$, and $15^{\#}$ groups are taken as examples to observe the test phenomena. It can be seen from Figure 9 that the $0^{\#}$ group, that is, the ordinary concrete specimens are broken into small pieces after being impacted, showing obvious brittle failure. With the increase of loading pressure (strain rate), the specimens are broken into small pieces accompanied by scattered powder particles, and the failure degree of the specimens increases rapidly. The $11^{\#}$ group is the specimen with the best static compressive strength; under $0.4 \mathrm{MPa}$ loading air pressure impact, the surface of the specimen appeared to have microcracks, but there was no fracture, and integrity remained relatively good; under $0.5 \mathrm{MPa}$ loading air pressure impact, the surface of the specimen began to appear more obvious cracks, but there was no fracture. Under the loading air pressure of $0.6 \mathrm{MPa}$, the surface cracks of the specimen showed a "trigeminal star shape" and fracture occurs. The $12^{\#}$ group is the specimen with the best static mechanical performance, none of the specimens appeared to have fracture under the impact of the three kinds of loading air pressure, the integrity of the specimens was maintained very well, and there was no brittle failure like ordinary concrete, showing a certain ductile failure characteristics. The $15^{\#}$ group is the specimen with the best static splitting tensile strength, and the failure of the specimen is more serious than that of the $11^{\#}$ and $12^{\#}$ groups; under the impact of $0.5 \mathrm{MPa}$ loading air pressure, a crack through the whole specimen is formed on the surface and the specimen fractured into two halves; with the increase of the impact loading air pressure, the specimen failure degree intensified. 


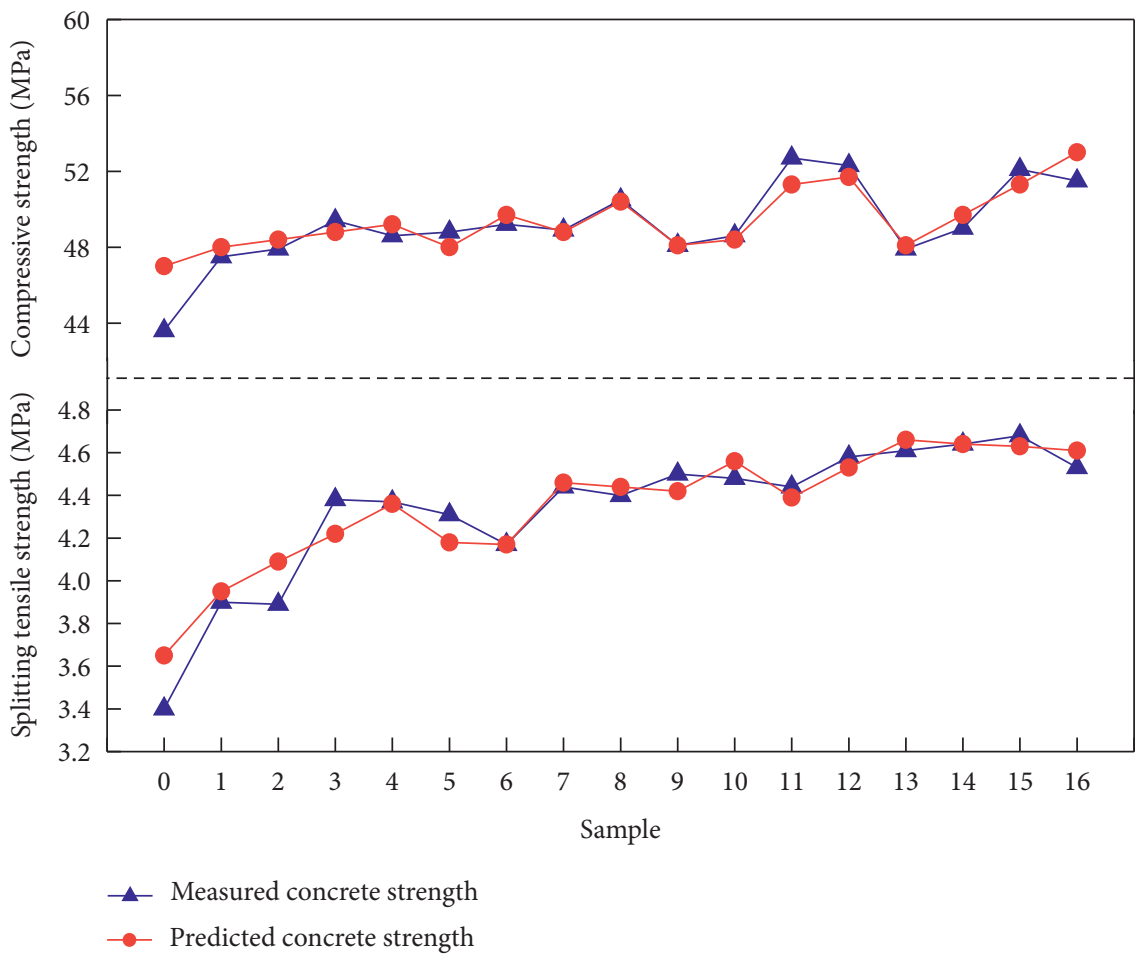

FIGURE 7: Comparison of predicted and measured values of HBPC compressive strength and split tensile strength.

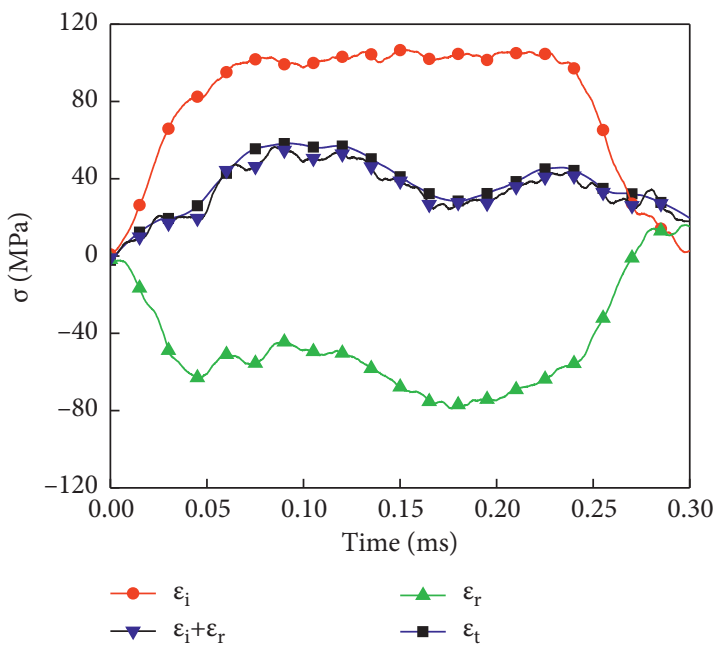

FIgURE 8: Stress balance verification.

4.3. Dynamic Compressive Strength. Table 8 shows the peak stresses of the benchmark concrete and HBPC under different loading air pressures impacts. It can be seen that the peak stresses of $16^{\#}$ groups of HBPC under different loading air pressures are all higher than that of benchmark concrete, which shows that the mixing of basalt fiber, polypropylene fiber and fly ash into concrete is beneficial to improve its dynamic compression mechanical properties; when the loading air pressure is $0.4 \mathrm{MPa}$, the peak stress of benchmark concrete is $21.1 \mathrm{MPa}$; when the loading air pressure is $0.5 \mathrm{MPa}$, the peak stress of benchmark concrete is $23.1 \mathrm{MPa}$, $9.48 \%$ higher than that at $0.4 \mathrm{MPa}$; when the loading air pressure continues to increase to $0.6 \mathrm{MPa}$, the peak stress of benchmark concrete is $24.4 \mathrm{MPa}, 15.64 \%$ higher than that at $0.4 \mathrm{MPa}$. This indicates that, with the increase of the loading air pressure, the peak stress (dynamic compressive strength) of the benchmark concrete is increasing, and both are higher than the cube compressive strength (20.3 MPa) of the benchmark concrete used in this test, showing a certain strain rate strengthening effect. Similar conclusions can be obtained by analyzing the dynamic compressive strength of HBPC in other groups, and this article will not repeat the description.

4.4. Stress-Strain Curve. Taking the $0^{\#}, 11^{\#}, 12^{\#}$, and $15^{\#}$ groups as examples for analysis, Figure 10 shows the stressstrain curves of the above four groups. It can be seen that, with the impact air pressure increase, the dynamic compressive strength, strain value, and plasticity of benchmark concrete and HBPC specimens also increase; the $0^{\#}$ group specimens show obvious brittle failure, and the stress-strain relationship of the $11^{\#}, 12^{\#}$, and $15^{\#}$ groups specimens can be divided into elastic stage, crack expansion stage, plastic deformation stage, and failure stage, and the stress in the plastic stage increases linearly with the increase of strain. After the elastic limit stress is reached, the internal microcracks of the specimen begin to expand and then enter the significant plastic deformation stage. With the slow increase of the dynamic strength, when the yield stress is reached, the strain of the specimen increases slightly, the stress decreases sharply, and the specimen is completely destroyed. 


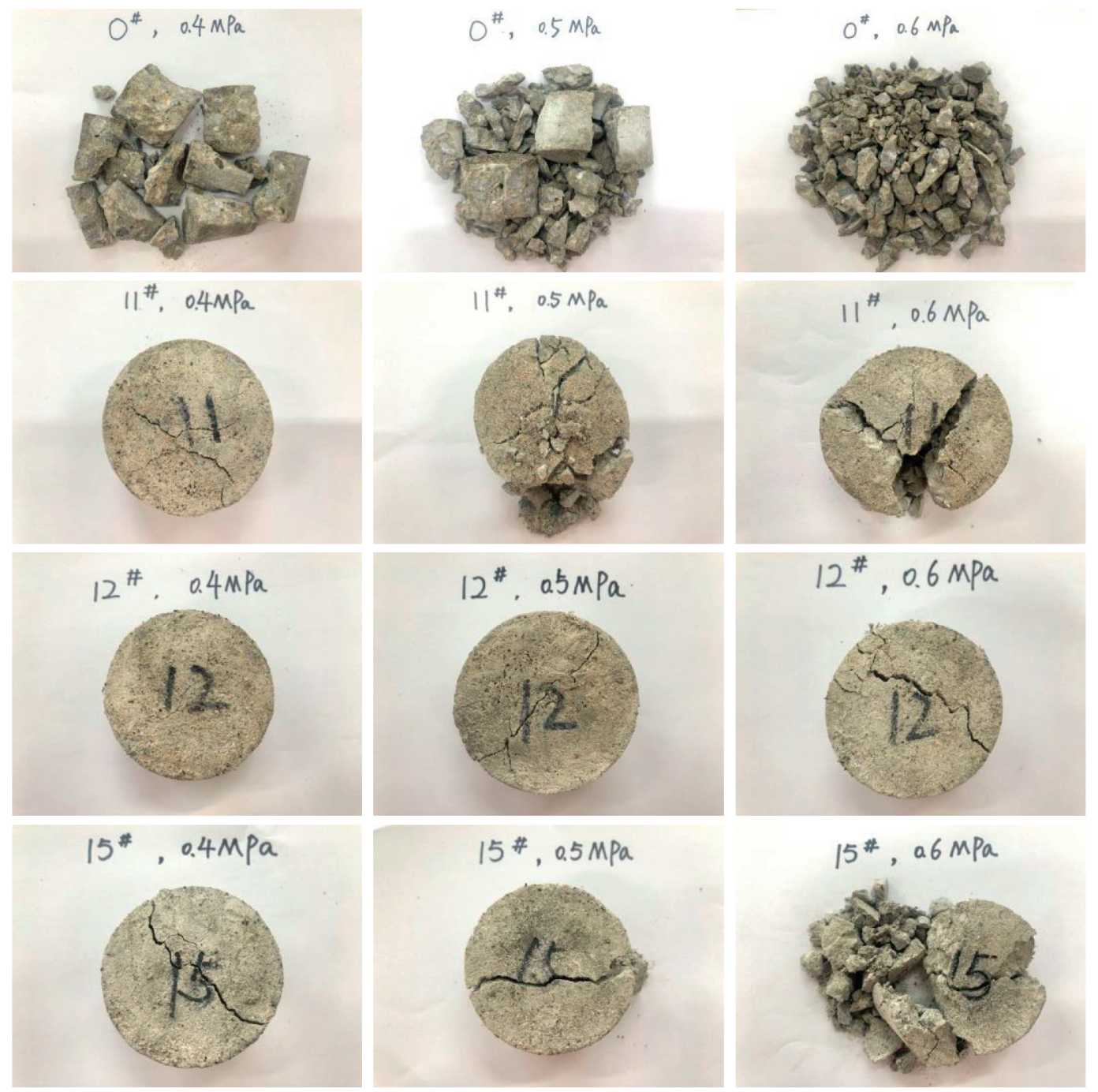

FIgURE 9: Failure mode of $0^{\#}, 11^{\#}, 12^{\#}$, and $15^{\#}$ group under $0.4 \mathrm{MPa}, 0.5 \mathrm{MPa}$, and $0.6 \mathrm{MPa}$ loading air pressure.

TABle 8: Peak stress of each group of specimens.

\begin{tabular}{lccc}
\hline Sample & & Peak stress $(\mathrm{MPa})$ & \\
& 0.4 & 0.5 & 0.6 \\
\hline $0^{\#}$ & 21.1 & 23.1 & 24.4 \\
$1^{\#}$ & 23.1 & 23.6 & 25.3 \\
$2^{\#}$ & 24.6 & 27.5 & 30.2 \\
$3^{\#}$ & 25.3 & 27.9 & 30.9 \\
$4^{\#}$ & 26.1 & 30.3 & 31.4 \\
$5^{\#}$ & 28.5 & 30.6 & 33.5 \\
$6^{\#}$ & 30.6 & 32.9 & 38 \\
$7^{\#}$ & 32.7 & 34.8 & 35.3 \\
$8^{\#}$ & 35.3 & 36.8 & 39.6 \\
$9^{\#}$ & 35.6 & 37.3 & 39.7 \\
$10^{\#}$ & 36.7 & 41.9 & 42.2 \\
$11^{\#}$ & 41.5 & 58.7 & 63 \\
$12^{\#}$ & 43.9 & 50.7 & 51.8 \\
$13^{\#}$ & 41.5 & 44.5 & 47.6 \\
$14^{\#}$ & 40 & 42.2 & 46.9 \\
$15^{\#}$ & 39.8 & 50.2 & 50.9 \\
$16^{\#}$ & 33 & 36.3 & 38.2 \\
\hline
\end{tabular}




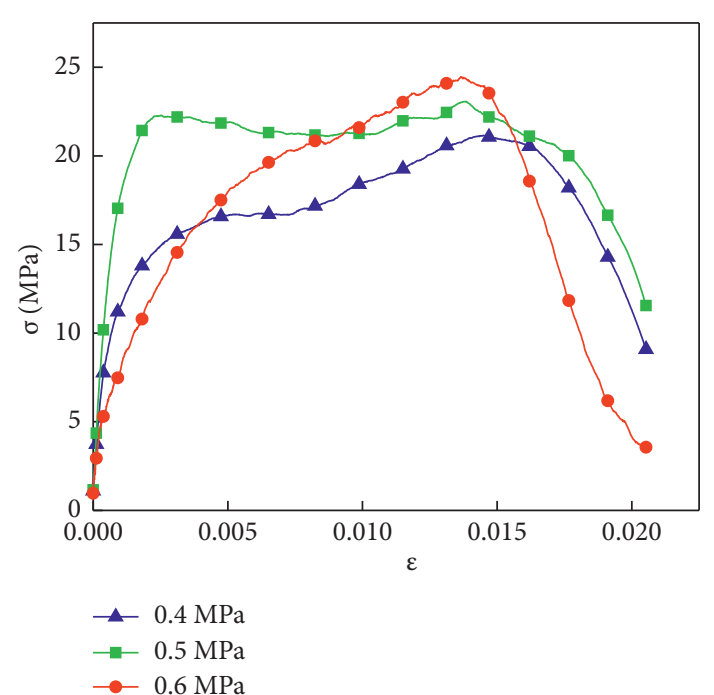

(a)

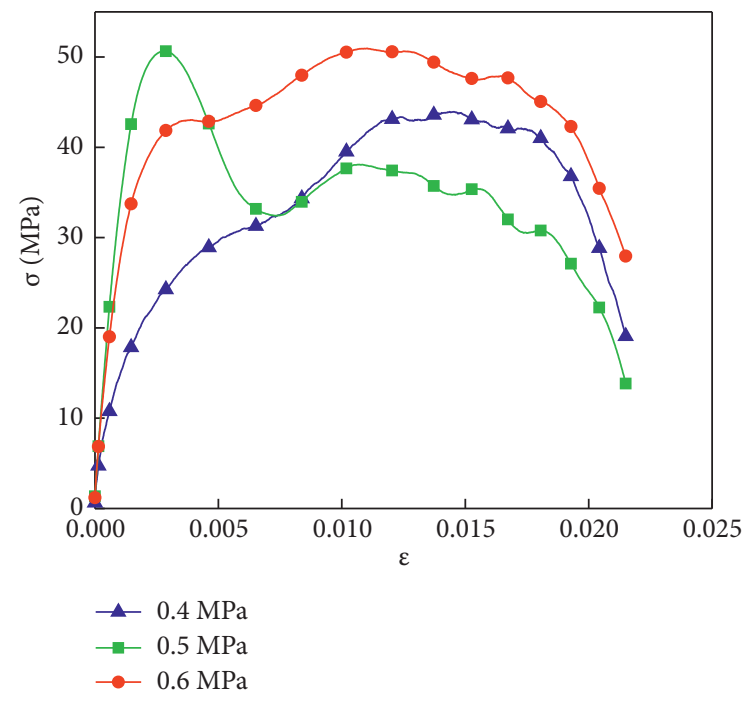

(c)

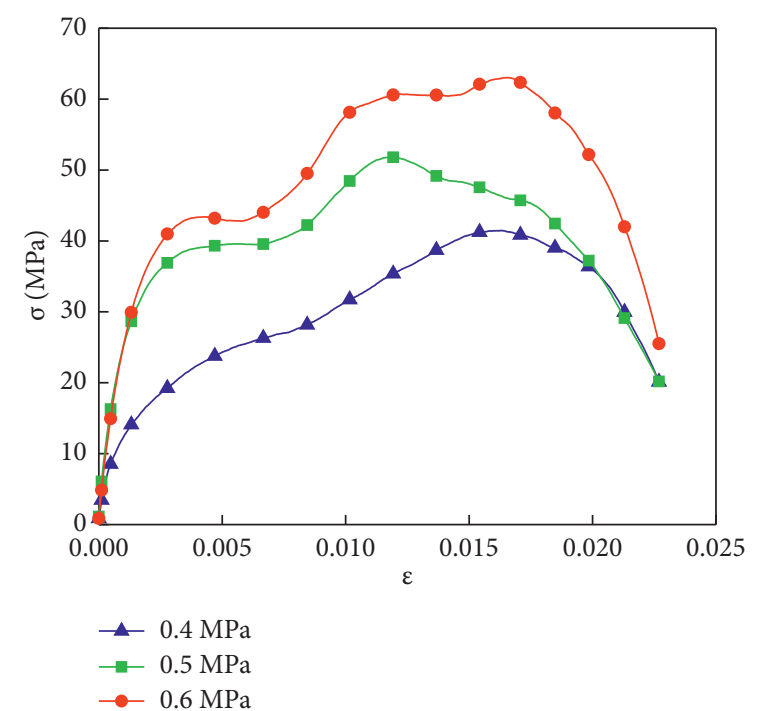

(b)

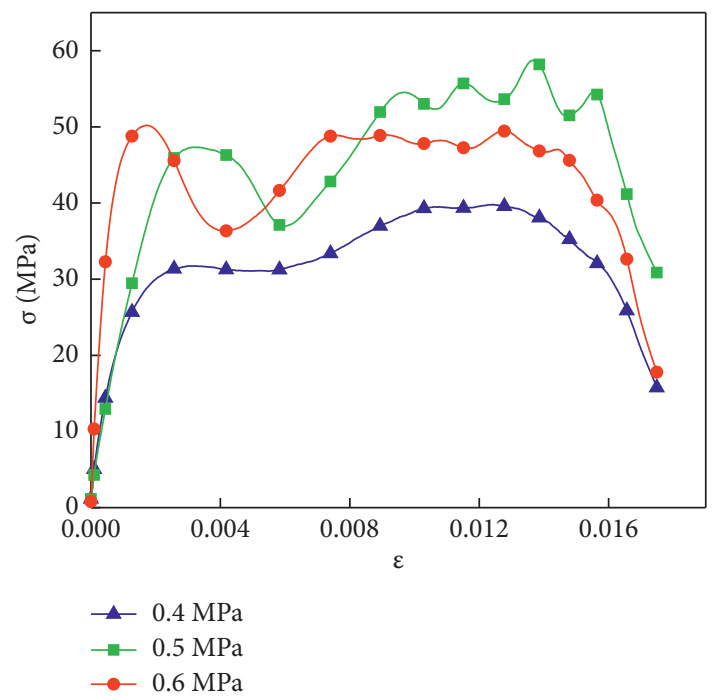

(d)

FiguRE 10: Stress-strain curves of HBPC under different loading air pressures. (a) $0^{\#}$ group. (b) $11^{\#}$ group. (c) $12^{\#}$ group. (d) $15^{\#}$ group.

4.5. Fiber Crack Resistance Effect of HBPC. Figure 11 shows the crack resistance mechanism model of HBPC [33]. It is obvious that mixing basalt fiber and polypropylene fiber into concrete has a good synergistic effect. On the one hand, polypropylene fiber has small size and large number. It exerts a good crack resistance effect in the crack generation stage of the dynamic compression performance test, delays the stress concentration at the tip of the microcrack stage, and can prevent the expansion of the microcrack. When microcracks develop into macrocracks, the stress is transferred from polypropylene fiber to basalt fiber. Because basalt fiber has the advantage of high elastic modulus, its deformation under tensile stress is small, and it can produce adhesive force and mechanical bite force with the concrete matrix, which inhibits the expansion of macrocracks, transfers the stress to the concrete on both sides of cracks, causes multiple cracks in the concrete, and delays the appearance of dynamic compression failure of the concrete. As the cracks continue to expand, the polypropylene fibers are broken and the basalt fibers are pulled out or slip in the concrete matrix can also absorb a large amount of dynamic compression energy. It can be seen that the hybrid of basalt fiber and polypropylene fiber can work synergy in different dynamic compression loading stages, play a crack resistance and reinforcement effect, effectively improve the dynamic compression resistance of concrete, improve the concrete's antidynamic compression performance effectively, and have better antidynamic compression performance than nonfiber and one kind of fiber.

\section{SEM Microanalysis}

It can be seen from Figure 12 that the exposed fiber surface is covered with dense thorn-like or spherical substances, which are mainly cement hydration matrix (C-S-H gel). During the hydration reaction of $\mathrm{HBPC}, \mathrm{C}-\mathrm{S}-\mathrm{H}$ gel and cement 

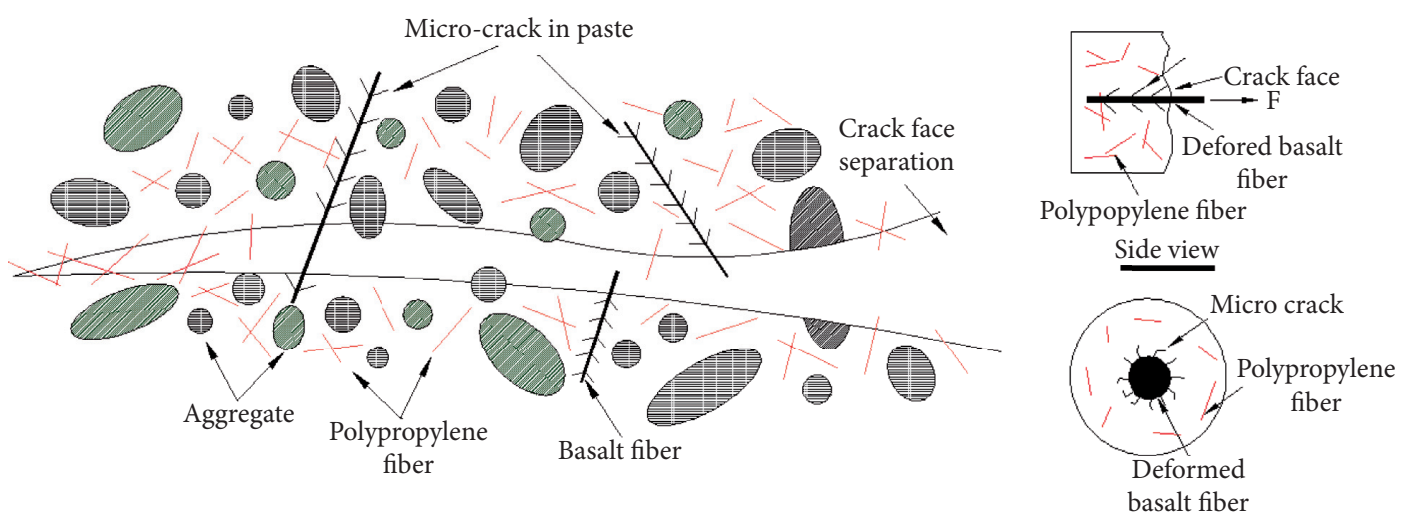

Figure 11: Crack resistance mechanism model of HBPC.
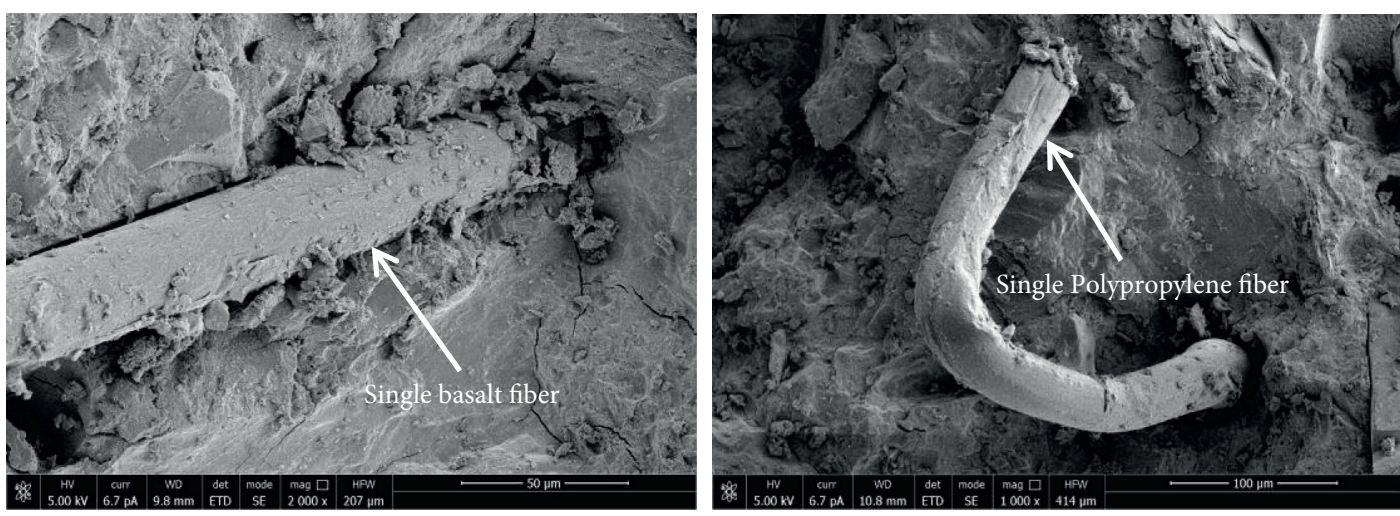

Figure 12: Fiber and matrix bonding.
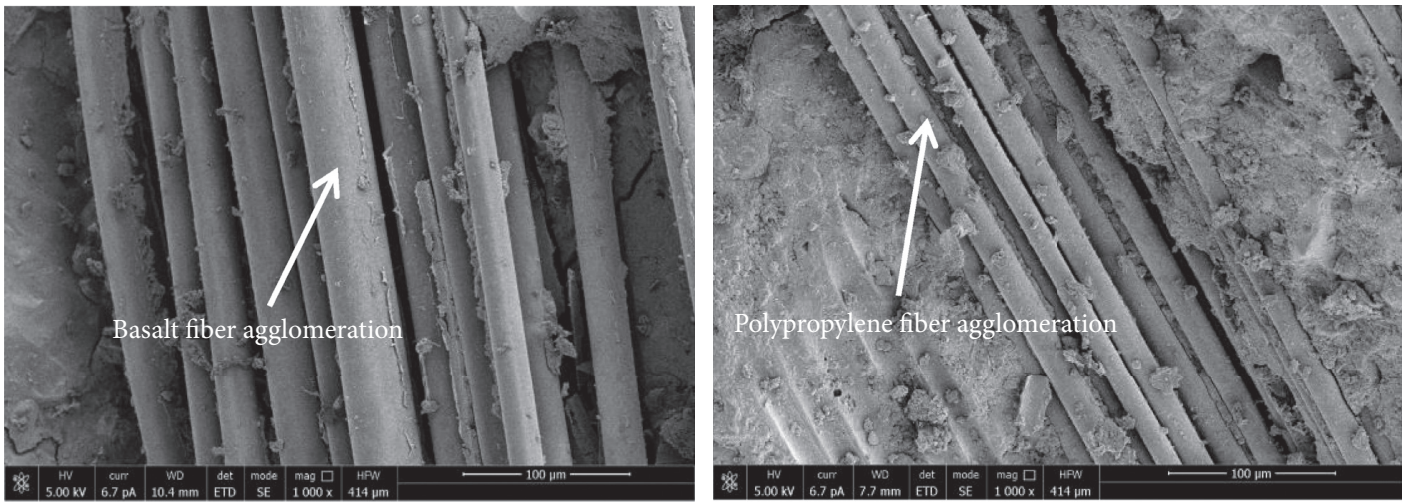

FIGURE 13: SEM image of HBPC fiber distribution and bonding.

secondary hydration product ettringite tightly wrap the fibers. When the fiber is under tension, it can form a certain mechanical bite force with the cement matrix, so the single fiber dispersed in the HBPC acts like a steel bar. The tight combination of fiber and concrete matrix plays the role of secondary microreinforcement. At the same time, the fiber interacts to form a three-dimensional network structure and the bridging effect of the fiber strengthens the bond between the fiber and the matrix, which effectively improves the mechanical properties of HBPC. It can be seen from Figure 13 that excessive fiber mixing into concrete will cause fiber agglomeration, which reduces the compactness of the concrete, affects the full bonding of the fiber and the concrete matrix, increases the internal defects of the concrete, and ultimately leads to the decrease of the strength of the concrete. 


\section{Conclusions}

(1) The static compressive strength and static splitting tensile strength of HBPC are both higher than those of benchmark concrete. The maximum increase of static compressive strength compared with the benchmark concrete is $20.87 \%$. The maximum increase of static splitting tensile strength compared with the benchmark concrete is $37.65 \%$.

(2) Basalt fiber and polypropylene fiber are extremely significant factors affecting the slump of HPBC, and the degree of influence of basalt fiber is greater than that of polypropylene fiber. Polypropylene fiber is the extremely significant factor affecting the compressive strength of $\mathrm{HPBC}$, and basalt fiber is the extremely significant factor affecting the splitting tensile strength of HPBC.

(3) Based on the efficacy coefficient method, the test results of slump, static compressive strength, and static splitting tensile strength of HBPC are comprehensively analyzed. The best combination of the three factors is $A_{3} B_{4} C_{2}$. According to the test results, the strength prediction model between the static compressive strength and static splitting tensile strength of HBPC was established. The prediction accuracy of the model is high, and it can provide reference for engineering practice.

(4) The integrity of the benchmark concrete remains poor after the dynamic compression test. The addition of basalt-polypropylene hybrid fiber and fly ash can inhibit the deformation and failure of concrete and improve the failure mode after dynamic compression load. With the increase of loading air pressure, the failure degree of the benchmark concrete and HBPC specimens increased, and the peak stress increased, showing a certain strain rate strengthening effect.

(5) At the loading air pressure of $0.4 \mathrm{MPa}$, the $12^{\#}$ group is when the basalt fiber volume ratio is $0.3 \%$, the polypropylene fiber volume ratio is $0.4 \%$, and the flyash replacing cement ratio is $10 \%$, and the peak stress is larger, and the dynamic compression properties are better. At the loading air pressure of $0.5 \mathrm{MPa}$ and $0.6 \mathrm{MPa}$, the $11^{\#}$ group is when the basalt fiber volume ratio is $0.3 \%$, the polypropylene fiber volume ratio is $0.3 \%$, and the fly-ash replacing cement ratio is $5 \%$, and the peak stress is larger, and the dynamic compression properties are better, which are closer to the test results of static compressive strength.

(6) With the help of SEM microanalysis, it can be known that the fibers can be well bonded to the concrete matrix, and the three-dimensional randomly distributed fibers form stable load-carrying structures inside the HBPC, which improves the internal stress distribution of the concrete matrix and inhibits the generation and expansion of cracks. However, excessive fiber incorporation will cause fiber agglomeration, which will affect the full bonding of the fiber and the concrete matrix, which is not conducive to the improvement of the mechanical properties of HBPC.

\section{Data Availability}

The data used to support the findings of this study are included within the article.

\section{Conflicts of Interest}

The authors declare that there are no conflicts of interest regarding the publication of this paper.

\section{Acknowledgments}

The research was financially supported by the Funding Project of Anhui University of Science and Technology (no. QN2019115) and Introduced Talent Research Funding of Anhui University of Science and Technology (no. 13190022).

\section{References}

[1] B. Nenad, B. Zhang, and J. Christopher, "Pearce relationship between brittleness and moisture loss of concrete exposed to high temperatures," Cement and Concrete Research, vol. 32, no. 3, pp. 363-371, 2002.

[2] C. Li, M. Zhao, X. Zhang, J. Li, X. Li, and M. Zhao, "Effect of steel fiber content on shear behavior of reinforced expandedshale lightweight concrete beams with stirrups," Materials, vol. 14, no. 5, p. 1107, 2021.

[3] B. Arisoy and H.-C. Wu, "Material characteristics of high performance lightweight concrete reinforced with PVA," Construction and Building Materials, vol. 22, no. 4, pp. 635645, 2008.

[4] D. L. Nguyen, D. J. Kim, G. S. Ryu, and K. T. Koh, "Size effect on flexural behavior of ultra-high-performance hybrid fiberreinforced concrete," Composites Part B: Engineering, vol. 45, no. 1, pp. 1104-1116, 2013.

[5] G. Xu and D. J. Hannant, "Synergistic interaction between fibrillated polypropylene networks and glass fibres in a cement-based composite," Cement and Concrete Composites, vol. 13, no. 2, pp. 95-106, 1991.

[6] M. Samaan, A. Mirmiran, and M. Shahawy, "Model of concrete confined by fiber composites," Journal of Structural Engineering, vol. 124, no. 9, pp. 1025-1031, 1998.

[7] T. Mészöly and N. Randl, "Shear behavior of fiber-reinforced ultra-high performance concrete beams," Engineering Structures, vol. 168, pp. 119-127, 2018.

[8] Z. Han, S. Zhao, and F. Qu, "Experimental study on the tensile performance of steel flber reinforced concrete," China Civil Engineering Journal, vol. 11, pp. 63-67, 2006.

[9] M. Papachristoforou and I. Papayianni, "Radiation shielding and mechanical properties of steel fiber reinforced concrete (SFRC) produced with EAF slag aggregates," Radiation Physics and Chemistry, vol. 149, pp. 26-32, 2018.

[10] H. Luo, D. Yang, X. Zhou, C. Shan, X. Liu, and F. Zhao, "Mechanical properties of polypropylene fiber reinforced concrete with different aspect ratios," Acta Materiae Compositae Sinica, vol. 36, no. 8, pp. 1935-1948, 2019.

[11] C. Quan, C. Jiao, Y. Yang, X. Li, and L. Zhang, "Orthogonal experimental study on mechanical properties of hybrid fiber 
reinforced concrete," Journal of Building Materials, vol. 22, no. 3, pp. 363-370, 2019.

[12] D. P. Dias and C. Thaumaturgo, "Fracture toughness of geopolymeric concretes reinforced with basalt fibers," Cement and Concrete Composites, vol. 27, no. 1, pp. 49-54, 2005.

[13] B. Li, Y. Chi, L. Xu, Y. Shi, and C. Li, "Experimental investigation on the flexural behavior of steel-polypropylene hybrid fiber reinforced concrete," Construction and Building Materials, vol. 191, pp. 80-94, 2018.

[14] M. Zhuo and X. Zhang, "Research on mechanical properties and durability of hybrid fiber reinforced concrete materials," Journal of Functional Materials, vol. 52, no. 01, pp. 1133-1138, 2021.

[15] V. M. de Alencar Monteiro, L. R. Lima, and F. de Andrade Silva, "On the mechanical behavior of polypropylene, steel and hybrid fiber reinforced self-consolidating concrete," Construction and Building Materials, vol. 188, pp. 280-291, 2018.

[16] I. S. Ibrahim, W. A. Wan Jusoh, A. R. Mohd Sam, N. A. Mustapa, and S. M. Sk Abdul Razak, "The mechanical properties of steel-polypropylene fibre composites concrete (HyFRCC)," Applied Mechanics and Materials, vol. 773-774, pp. 949-953, 2015.

[17] W. Yao, J. Li, and K. Wu, "Mechanical properties of hybrid fiber-reinforced concrete at low fiber volume fraction," $\mathrm{Ce}$ ment and Concrete Research, vol. 33, no. 1, pp. 27-30, 2003.

[18] J. Khunthongkeaw, S. Tangtermsirikul, and T. Leelawat, "A study on carbonation depth prediction for fly ash concrete," Construction and Building Materials, vol. 20, no. 9, pp. 744753, 2006.

[19] O. Karahan and C. D. Atiş, "The durability properties of polypropylene fiber reinforced fly ash concrete," Materials \& Design, vol. 32, no. 2, pp. 1044-1049, 2011.

[20] S. C. Kou, C. S. Poon, and D. Chan, "Influence of fly ash as cement replacement on the properties of recycled aggregate concrete," Journal of Materials in Civil Engineering, vol. 19, no. 9, pp. 709-717, 2007.

[21] M. Rafieizonooz, J. Mirza, M. R. Salim, M. W. Hussin, and E. Khankhaje, "Investigation of coal bottom ash and fly ash in concrete as replacement for sand and cement," Construction and Building Materials, vol. 116, pp. 15-24, 2016.

[22] A. Caggiano, S. Gambarelli, E. Martinelli, N. Nisticò, and M. Pepe, "Experimental characterization of the post-cracking response in hybrid steel/polypropylene fiber-reinforced concrete," Construction and Building Materials, vol. 125, pp. 1035-1043, 2016.

[23] W. Huang, W. Quan, and P. Ge, "Orthogonal tests investigation into hybrid fiber-reinforce recycled aggregate concrete and convolutional neural network prediction," Journal of Asian Architecture and Building Engineering, vol. 14, pp. 1-16, 2021.

[24] N. Elias, R. A. Wahab, L. W. Jye, N. A. Mahat, S. Chandren, and J. Jamalis, "Taguchi orthogonal design assisted immobilization of Candida rugosa lipase onto nanocellulose-silica reinforced polyethersulfone membrane: physicochemical characterization and operational stability," Cellulose, vol. 28, no. 9, pp. 5669-5691, 2021.

[25] X. Xu, Y. Gu, W. Huang, D. Chen, C. Zhang, and X. Yang, "Structural optimization of steel-epoxy asphalt pavement based on orthogonal design and GA-BP algorithm," Crystals, vol. 11, no. 4, p. 417, 2021.

[26] Z. Yao and J. Zhou, "Study on fracture energy of reactive powder concrete reinforced by steel-polypropylene hybrid fiber," Journal of Building Materials, vol. 8, no. 4, pp. 356-360, 2005.

[27] L. Xu, B. Li, Y. Chi, B. Huang, and Y. Shi, "Experimental investigation on the stress-strain relation of steel-polypropylene hybrid fiber reinforced concrete subjected to uniaxial cyclic compression," Journal of Building Structures, vol. 39, no. 4, pp. 140-152, 2018.

[28] R. Dong, B. Xiao, and Y. Fang, "The theoretical analysis of orthogonal test designs," Journal of Anhui Institute of Architecture, vol. 6, p. 029, 2004.

[29] C. Wang, A. Wang, and X. Zhang, "Effect of dispersion of short carbon fibers on the mechanical properties of CFRC composites," Materials Reports, vol. 134, pp. 125-128, 2007.

[30] Z. Deng, X. Liu, X. Yang et al., "A study of tensile and compressive properties of hybrid basalt-polypropylene fiberreinforced concrete under uniaxial loads," Structural Concrete, vol. 22, no. 1, pp. 396-409, 2021.

[31] Q. Fu, D. Niu, J. Zhang, D. Huang, and M. Hong, "Impact response of concrete reinforced with hybrid basalt-polypropylene fibers," Powder Technology, vol. 326, pp. 411-424, 2018.

[32] D. Li, Z. Han, Q. Zhu, Y. Zhang, and P. G. Ranjith, "Stress wave propagation and dynamic behavior of red sandstone with single bonded planar joint at various angles," International Journal of Rock Mechanics and Mining Sciences, vol. 117, pp. 162-170, 2019.

[33] B. Li, L. Xu, Y. Shi, Y. Chi, Q. Liu, and C. Li, "Effects of fiber type, volume fraction and aspect ratio on the flexural and acoustic emission behaviors of steel fiber reinforced concrete," Construction and Building Materials, vol. 181, pp. 474-486, 2018. 